\title{
CORRECTION
}

\section{Correction to: Variation in stalk rot resistance and physiological traits of sorghum genotypes in the field under high temperature}

Ramasamy Perumal ${ }^{1}$ (D) Sandeep S. Tomar ${ }^{1} \cdot$ Ananda Bandara $^{2} \cdot$ Djanaguiraman Maduraimuthu $^{3} \cdot$ Tesfaye T. Tesso $^{4}$. P. V. Vara Prasad ${ }^{4} \cdot$ Hari D. Upadhyaya ${ }^{5} \cdot$ Christopher R. Little $^{6}$

Published online: 11 August 2020

(c) The Phytopathological Society of Japan and Springer Japan KK, part of Springer Nature 2020

Correction to: Journal of General Plant Pathology https://doi.org/10.1007/s10327-020-00940-4

In the original publication of the article, Fig. 2 was repeated as Fig. 1. The correct Figs. 1 and 2 are published in this correction.

The original article can be found online at https://doi.org/10.1007/ s10327-020-00940-4.

Ramasamy Perumal perumal@ksu.edu

1 Agricultural Research Center, Kansas State University, Hays, KS, USA

2 College of Agricultural Sciences, Penn State University, University Park, State College, PA, USA

3 Department of Crop Physiology, Tamil Nadu Agricultural University, Coimbatore, Tamil Nadu, India

4 Department of Agronomy, Kansas State University, Manhattan, KS, USA

5 ICRISAT, Patancheru, Telangana, India

6 Department of Plant Pathology, Kansas State University, Manhattan, KS, USA 
Traits (PC1 and $\mathrm{PC} 2: 57.7 \%)$

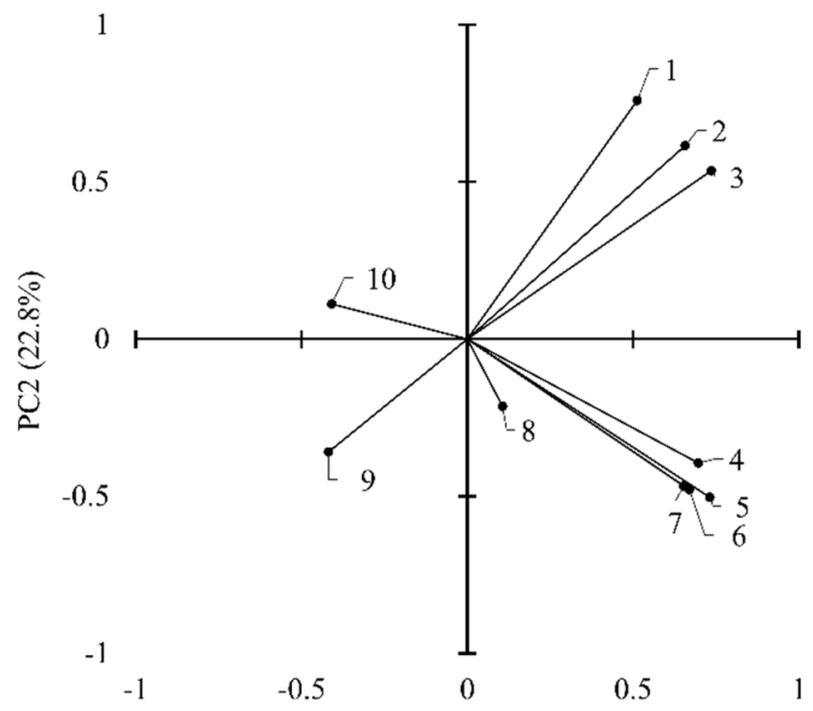

PC1 $(34.8 \%)$
Genotypes (PC1 and PC2: $57.7 \%$ )

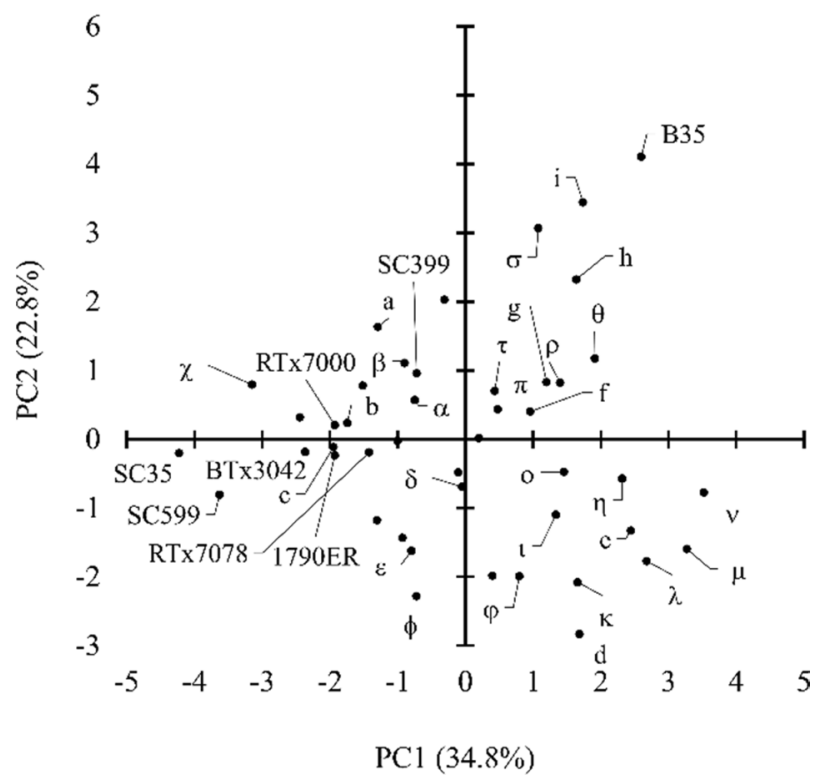

M. phaseolina, (7) lesion length in control, (8) leaf temperature, (9) PS II quantum yield ( $\mathrm{F}_{\mathrm{v}} / \mathrm{F}_{\mathrm{m}}$ ratio), and (10) chlorophyll index (SPAD units). b Abiotic and biotic stress control line designations are spelled out. PI lines are indicated as: $a$ PI 267379, $b$ PI534052, $c$ PI533946, $d$ PI536516, $e$ PI548007, $f$ PI568323, $g$ PI563253, $h$ PI565174, $i$ PI475432. The IS lines are indicated as: $\alpha$ IS29582, $\beta$ IS2864, $\chi$ IS19262, $\delta$ IS14290, $\varepsilon$ IS26749, $\phi$ IS5094, $\eta$ IS24492, $l$ IS2397, $\varphi$ IS24365, $\kappa$ IS3971, $\lambda$ IS2426, $\mu$ IS30533, $\nu$ IS23992, $o$ IS30508, $\pi$ IS24348, $\theta$ IS12883, $\rho$ IS29233, $\sigma$ ICSR8905, and $\tau$-IS13782 


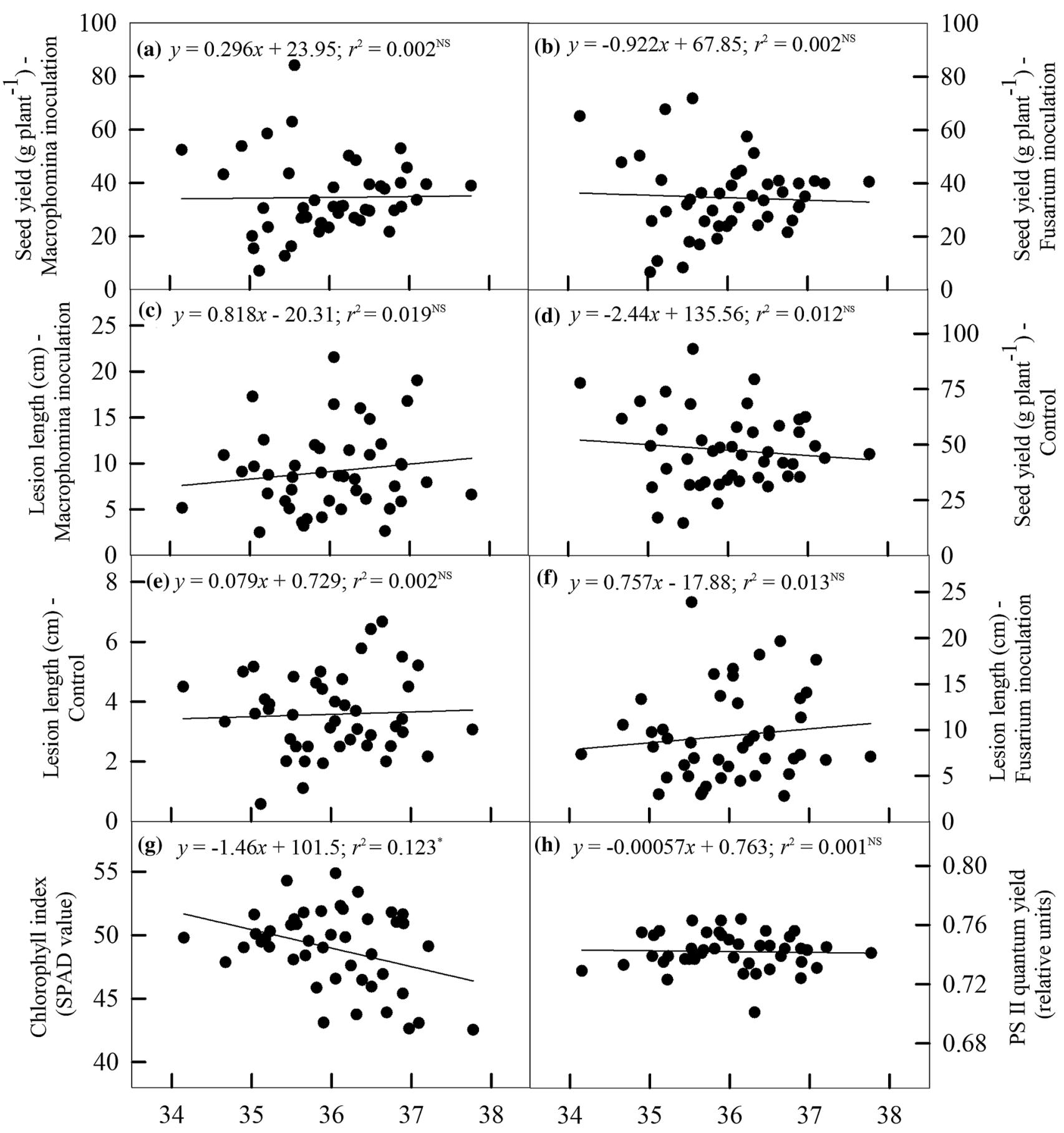

Leaf temperature $\left({ }^{\circ} \mathrm{C}\right)$

Fig. 2 Linear relationships between leaf temperature $\left({ }^{\circ} \mathrm{C}\right)$ and seed yields (g per plant), lesion lengths (cm), chlorophyll index (SPAD), and photosystem II quantum yield. FT Fusarium thapsinum, MP Macrophomina phaseolina 